\title{
Measuring Customer Perceived Hi-Tech New Product Performance: A Study of PDA Products
}

\author{
Zhilin Yang \\ City University of Hong Kong, Kowloon, Hong Kong
}

\begin{abstract}
This study intends to expand the extant body of knowledge of customer-oriented and product attribute-based measures of new product performance. Based on personal interviews and a field survey of users of Personal Digital Assistants (PDA), we identify six key product dimensions perceived by customers. The results indicate that while customers employ a set of dimensions to judge a PDA product, each dimension is weighted differently in determining new product performance. Only two dimensions, upgradeability/supports and portability, significantly influence overall performance. Customer demographic and product usage variables have no direct impact on performance. In addition, we examine the relationships between six major quality dimensions and overall performance and find that they do not significantly vary in terms of product types and customer geographical locations. The strength of some dimensions on customers' overall performance evaluation of new product varies depending on the purpose of product usage. Our findings have important implications for new product performance evaluation and market segmentation.
\end{abstract}

Keywords: New Product Development, Performance Evaluation, Customer Orientation, Market Segmentation

Publication Details: Received 5 Jan 2018; Revised 20 Mar 2018; Accepted 14 May 2018 


\section{Introduction}

Technology firms often operate in a highly competitive and swiftly changing market environment, coupled with shorter product lifecycle and higher rates of technical obsolescence. Thus, product innovation or new product development (NPD), as the nexus of competition, has become ever more critical for a firm to meet rapidly evolving customer needs and wants, and to gain competitive advantage (Bharadwaj, Bharadwaj and Bendoly, 2011). New product development has been studied in terms of effective responsiveness to the market for years (Lambert and Slater 1999; Huang, Soutar, and Brown, 2004; Ledwith and O'Dwyer 2009). When it comes to performance measurement of NPD, however, few companies have employed measures that reflect (1) key aspects perceived by customers, and (2) firm business strategies such as customer satisfaction and product quality in a competitive market (Hertenstein and Platt 2000; Ledwith and O'Dwyer 2009).

Ideally, NPD project success should embrace three distinct aspects: consumer-based, financial, and technical or process-based success (Griffin and Page 1993; Ledwith and O'Dwyer 2009). In reality, however, such a perfect NPD is virtually non-existent. Thus, priorities have to be set for all realistic NPD performance evaluations. As customers have become more actively involved in the process of NPD, the input of customers' perceptions is vital to leveraging impact on ways new products are being developed and on ways in which their performance is being measured (Griffin 1997).

Our study focuses on consumer-based measures of NPD success. In practical terms, developing customer-based measures requires managers to clearly understand the following critical issues:

1. What are the key quality dimensions used by customers in evaluating product performance?

2. Do these critical attributes significantly impact customers' overall evaluation? Which are most important and which are less so?

3. Is the strength of the effect of each major attribute on customer evaluation of NPD moderated by (1) product types; (2) geographical locations; and/or (3) customer usage patterns?

4. Do customer demographic variables affect their evaluation of NPD?

Only a moderate number of studies have been devoted to developing customer-based measurement of NPD performance by taking the above issues into account. The purpose of this study, thus, intends to fill the preceding gap in literature.

From a theoretical perspective, this research intends to expand existing knowledge of customer-based evaluations of NPD performance by identifying customer perceived key quality dimensions and linking these attributes to overall performance evaluation. We further investigate whether the relationships between key dimensions and overall performance evaluation are moderated by customer characteristics. 
The paper is organized in the following ways. After a literature review of relevant studies, we develop a conceptual framework of customer-oriented and attributes-based performance measures of NPD and propose four hypotheses. We conducted a focus group study, personal interviews, and a field survey of PDA users to identify and verify key product quality attributes. Based on results pertaining to four hypotheses, we finally provide strategic implications of our findings and point out some limitations and research directions for future studies.

\section{Conceptual Framework and Hypothesis}

Measuring NPD performance has been extremely difficult because no single measure is sufficient. Griffin and Page (1996) have pointed out that the most appropriate measures of project-level and program-level successes are contingent on business strategies and product strategies. They identified four business strategies, namely prospector, analyzer, defender, and reactor, and six product strategies, specifically new-to-the-world, new-tothe-company, product improvement, line extensions, repositionings, and cost reductions. Regarding project-level success measures, customer-based metrics play a vital role. Customer-based success consists of customer satisfaction, customer acceptance, market share, revenue goals, revenue growth goals, unit volume goals, and number of customers (Griffin and Page 1996; Sandmeier, Morrison and Gassmann). Our research focuses mainly on the first two aspects, customer satisfaction and customer acceptance, due to two major reasons. Firstly, Griff and Page (1996) have found that customer satisfaction was the most frequently mentioned measure for projects involving new-to-the-world, new-to-the-company product, product improvement, repositionings, and cost reduction; and customer acceptance was the most useful measure for projects involving repositionings, new-to-the world, and cost reductions.

Second, because of the unique nature of NPD, Hertenstein and Platt $(1997,2000)$ have noted that financial measures, such as profit goals, margin goals, or ROI, suffer three major weaknesses. While financial metrics have advantages in measuring planning and monitoring activities, they are less effective in evaluating NPD performance as it is a reward activity. The second drawback resides in the realization that the long-term nature of NPD, coupled with the lag between NPD work and financial performance in the market, makes it difficult to measure the financial performance of NPD. Finally, the difficulty in separating individual contributions to NPD makes financial measures extremely difficult. As such, NPD managers prefer non-financial measures that reflect critical strategic dimensions such as customer satisfaction, customer acceptance, and product quality (Griffin and Page 1996; Hertenstein and Platt 1997).

\section{Triangle Perspectives of Measuring NPD Performance}

We propose a triangle approach in developing customer-based measures of NPD performance by incorporating three components: company, competitors, and customers (see Figure 1). Effective measures of NPD performance should incorporate these three

perspectives. While the company perspective is internally oriented, the customer and competitors' perspectives are externally oriented. 


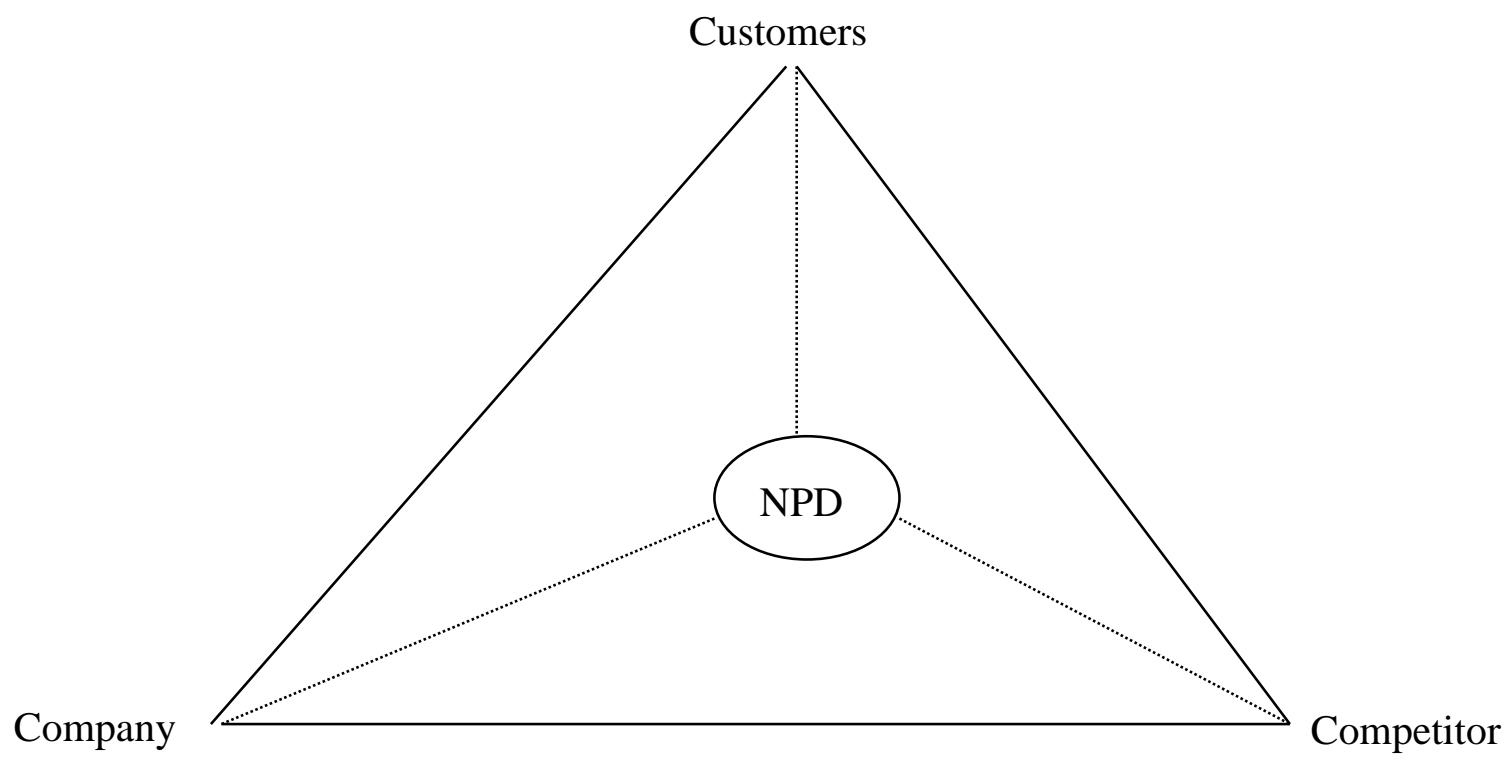

Figure 1: Triangle Perspective of NPD Performance

The internal measures of NPD performance are vast and rich, including on-time delivery of development projects, actual project cost compared to the budget, actual vs. target time for project completion, field trials prior to product, projected profitability analysis, product failure rates, and supplier lead time (Driva, Pawar, and Menon 2000). Nevertheless, external measures that integrate feedback from existing and potential customers have been seldom used and even ignored (Lambert and Slater 1999). Customer satisfaction and acceptance are frequently directly judged by customers and are often measured by surveying customers. Figure 2 shows the theoretical framework. 


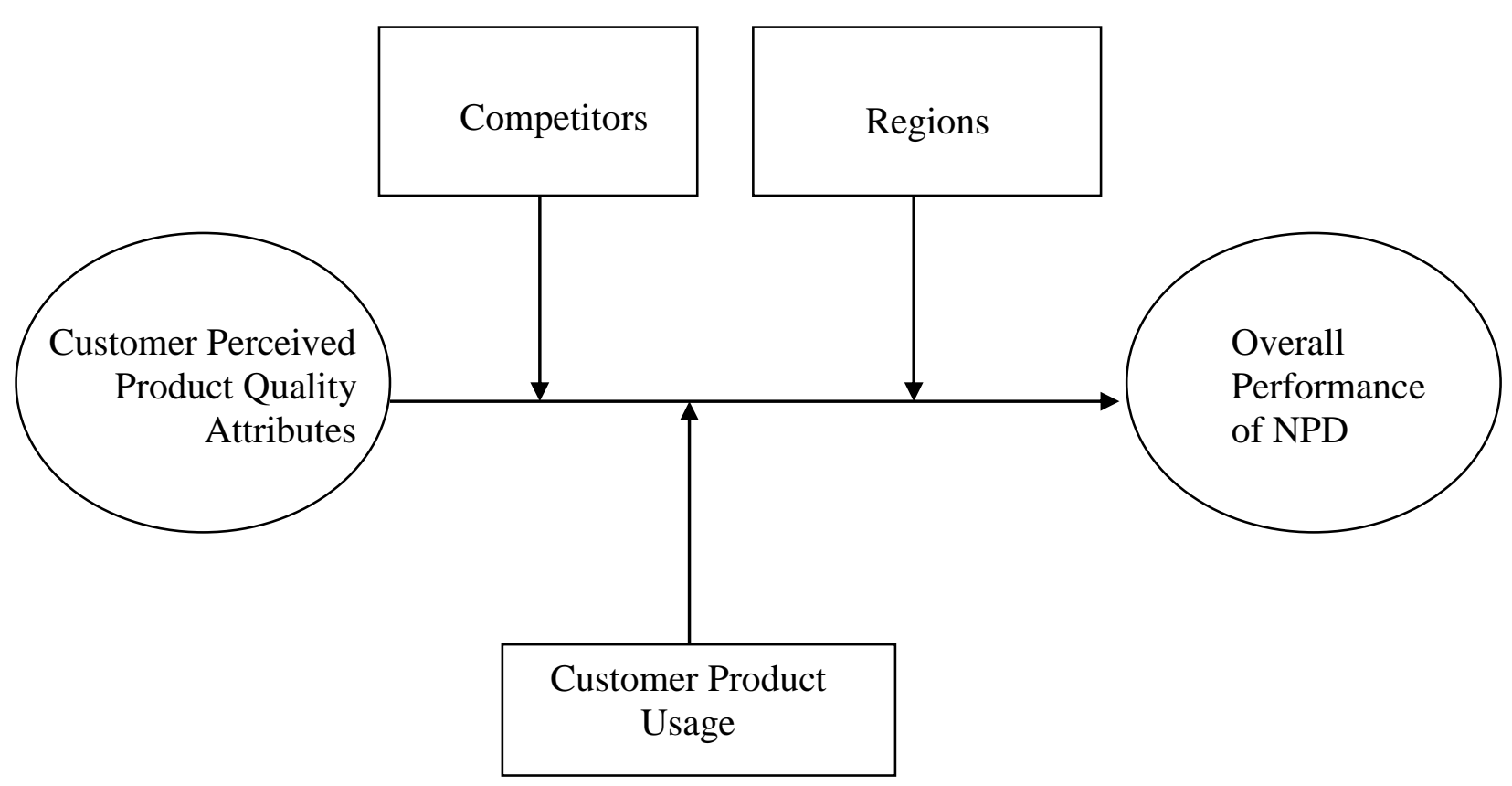

Figure 2: Conceptual Model

\section{Attribute-based Customer Evaluation of NPD Performance}

Compared to other measures, such as financial measures, customer-based measures have one major advantage in promptly responding to the market. In fact, linking performance measures of NPD to firm business strategies is essential (Kaplan and Norton 1992; Langfield-Smith 1997), although the integration has been weak (Griffin and Page 1996; Hertenstein and Platt 2000). Some critical strategic dimensions include customer satisfaction, time to market, and product quality. To measure product quality and customer satisfaction, attribute-based measures of product quality and customer satisfaction is a common practice in both the business and academic world (Kahn 1991; Sanbonmatsu, Kardes, and Gibson 1991; Zhang and Fitzsimons 1999). The question raised is: how can key quality attributes of a new product be identified? Although product developers, technical experts, marketers, and consumers have various perceptions of a new product, customer perceptions count and matter most.

Customers tend to evaluate a new product, which is uncertain in nature, on the basis of important attributes (Kahn 1991; Wright 1975). For instance, ease of use is one of the most frequently mentioned features for customers who adopt a new information technology product (Davis 1989; Davis, Bagozzi, and Warshaw 1989). Customers' perceived product quality attributes are often different from those of product designers, developers, and marketers in a firm. Thus, identifying key product quality attributes, judged by customers, is a necessary step in evaluating NPD performance.

Additionally, unless a product is totally "new-to-the-world" (Griffin and Page 1996), it usually has similar products and substitutes available on the market. For instance, when Compaq develops a new type of PDA, not only will it target one or more new customer 
segments, but also existing users from its major competitors, i.e., Palm. To gain more market shares and competitive advantage, it is desirable for a firm to recognize the needs and wants of customers from its competitor. Specifically, marketers need to understand whether competitors' customers have the same perception as their own company users, with reference to the effect of each product attribute on their overall performance evaluation.

From the customer perspective, customer satisfaction and customer acceptance are two effective measures of overall new product performance (Griffin and Page 1996). A customer often evaluates a new product based on a set of criteria which mainly consist of important product quality attributes and the product cost. When customers develop critical attributes to evaluate a NP, we assume that each attribute will significantly contribute to overall NP performance. For this reason, we offer the following hypothesis:

H1: Each product quality dimension will positively impact customers' evaluation of overall performance of NPD

\section{Customer Profile and NPD Performance}

We argue that overall NPD performance may vary across customers or users. Researchers have employed customer sociodemographic and product usage variables as bases to segment target markets (Wedel 1998). Understanding customer demographic variables

and product usage factors that directly influence their evaluation on NPD performance can help a firm design marketable products and target the right consumers.

Customers are not homogeneous in terms of their sociodemographic background such as age, income, education level, and the like. Additionally, their usage frequency and intensity of same products are often different. In our focus group study and personal interviews, most participants felt that the product usage variables were better predictors than the demographic variables. Thus, we formulate the following hypotheses:

H2a: The perceived performance of a high-tech NPD will not be significantly affected by customers' sociodemographic variables including age, income, and education level.

$H 2 b$ : The perceived performance of a high-tech NPD will be significantly affected by at least customers' product usage frequency and intensity.

\section{The Moderating Effect of Product Types and Regions}

Finally, we maintain that other factors such as geographic locations, product applications may also play a moderating role in the relationships between each key quality attribute and overall NPD performance. For instance, as almost all high-tech new products tend to target global customers, international marketers certainly wonder whether customers from different regions have the same requirements for each critical product quality attributes. 
Specifically, we consider three major moderators: types of products or brands, geographical locations, and product applications. Customers often apply one product in different ways. For instance, a Personal Digital Assistant (PDA) might serve various purposes including an electronic organizer, email and messaging, document and spreadsheet processing, and games. We assume that the relationships between product attributes and customer overall performance will be significantly moderated by these three factors. Therefore,

H3: In determining the customer perceived performance of a high-tech NPD, the importance of each key product quality attribute will significantly differ across

(a) products from different companies;

(b) regional markets; and

(c) product applications.

\section{Research Design and Method}

\section{Development of Product Quality Attributes}

In terms of the nature of this study, we decided to choose one high-tech product which has a global presence, the Personal Digital Assistant (PDA), to investigate our hypotheses. A PDA is a hand-held computer that allows a person to store, access, and organize information. A simple PDA can commonly serve as a personal organizer for storage of contact information, a calendar, a task list, and a note pad. For example, a salesperson may retrieve customer information, product information, or sales order status through a PDA. More sophisticated PDA products provide functions such as document and spreadsheet processing, multimedia player, gaming, wireless phone, internet access, email and messaging, etc. Although numerous hardware manufacturers in this burgeoning industry are providing different versions of the PDA, most PDA products run on either a Windows-based or a Palm operating system. Currently, PDA operating systems are dominated by Microsoft and Palm. Most manufacturers have stopped producing their own proprietary software operating system (OS), but have adopted either the Microsoft Pocket PC or the Palm operating system.

Because developing key quality attributes of PDA products is critical for this study, we employed multiple ways to ensure the appropriate identification of major attributes. First, we conducted a half-hour group meeting with three staff members at Microsoft Corporation in Hong Kong who were involved in product development and marketing activities related to PDA products. We chose Microsoft because of our research accessibility to this company.

While these attributes do provide useful insights, they were mainly based on experts' judgment, subject to technical biases. Thus, we further conducted personal interviews with five individual PDA users with various backgrounds. The meetings ranged from 30 
minutes to one hour. Based on these three sources, we developed eight key product quality dimensions and gathered an initial pool of 30 items for each dimension.

We further asked five interviewees to sort the importance of 30 items. Ten items along with three dimensions were dropped since they reflected the lowest levels of importance. We also reworded some statements to make them clearer by taking into account interviewees' feedback. As a result, six dimensions with 20 items were developed. They were upgradeability and support, portability, application, performance, design, connectivity, and ease of use.

\section{Overall NPD performance}

In this study, we utilized four scale items to measure overall NPD performance. As suggested by previous studies (i.e., Griff and Page 1996), we adopted items relevant to customer satisfaction and acceptance of new products. Respondents were asked to rate overall product performance, perceived product value, customer repurchase intention, and intention to recommend to friends and relatives. This construct was reliable and valid, as evidenced by (1) all items loading on one factor with coefficients above 0.4 and T-values all reaching significance; and (2) the Crobach alpha of this construct was 0.79 and the composite reliability of these four items was 0.81 .

\section{The Final Survey}

The survey consisted of three parts. In the first part, respondents indicated on which companies' operating systems their PDAs were running, Microsoft Pocket PC/Win CE, Palm OS, or others. Respondents were then asked to rate 24 items (20 items for six quality attributes of PDA products and 4 for overall NPD performance). In the second part, we included customer product usage patterns, such as usage frequency, usage intensity, and most frequently-used applications.

The last part was customer sociodemographic variables, including sex, age, education level, monthly income, and geographical locations. Due to differences in telecom standards and use requirements, Microsoft divides the world market into three regions (1) the Americas, (2) Europe, Middle East and Africa, and (3) Asia and the South Pacific. Microsoft offers localized versions of PDA operating systems for different regions. The current research focused on two regions: Asia and the South Pacific, and the Americas.

\section{Data Collection}

We employed the Web-based survey method to collect data. Since our target sample was PDA users, we obtained a list of 900 customers provided by an international PDA vendor as a sample frame. We randomly selected 460 user names with email addresses. A total of 460 e-mail invitations were sent out with a URL address. Additionally, on the survey, were a fax number and a physical mailing address. We also attached the questionnaire to the email. Thus, email recipients had multiple channels to return finished questionnaires. 
They could fill in the questionnaire online, then use email, fax, or mail the questionnaire back to us.

As a result, a total of 333 persons returned the questionnaires. After data screening, we deleted 16 incomplete and disqualified questionnaires, 317 copies were useful with an effective response rate of $69 \%$. We further excluded 26 respondents whose PDAs were running on operating systems other than Microsoft and Palm because its size was too small to derive any meaningful conclusions. Thus, we utilized a total of 291 effective samples for further study.

Table 1: Profile of Respondents Based on Operating Systems

\begin{tabular}{|c|c|c|c|c|c|}
\hline & & & \multirow[b]{2}{*}{$\begin{array}{l}\mathrm{MS}^{1} \\
\%\end{array}$} & \multirow[b]{2}{*}{$\begin{array}{l}\text { Palm }^{2} \\
\%\end{array}$} \\
\hline & $\begin{array}{l}\text { MS }^{1} \\
\%\end{array}$ & $\begin{array}{l}\text { Palm }^{2} \\
\%\end{array}$ & & & \\
\hline Classification & $\mathrm{N}=189$ & $\mathrm{~N}=102$ & Classification & $\mathrm{N}=189$ & $\mathrm{~N}=102$ \\
\hline Gender & & & How often do you use your PDA & & \\
\hline Male & $69.8^{3}$ & 60.8 & Every day & 49.7 & 41.2 \\
\hline Female & 28.6 & 38.2 & 4 to 6 days a week & 12.7 & 13.7 \\
\hline Age & & & 2 to 3 days a week & 18.0 & 16.7 \\
\hline $20-29$ & 14.8 & 19.6 & Once a week or less & 14.8 & 19.6 \\
\hline $30-39$ & 79.9 & 78.4 & On average, how long do you us & & \\
\hline $40-49$ & 3.7 & 1.0 & your PDA at a time? & & \\
\hline Education & & & 5 to 15 minutes & 39.2 & 55.9 \\
\hline Secondary/College & 5.3 & 2.0 & 15 to 30 minutes & 40.2 & 30.4 \\
\hline University & 47.6 & 49.0 & 30 to 60 minutes & 8.5 & 3.9 \\
\hline Post Graduates & 45.0 & 47.1 & 1 to 2 hours & 7.9 & 3.9 \\
\hline Monthly Income & & & What applications do you use? & & \\
\hline$<\mathrm{US} \$ 1,500$ & 2.1 & 6.9 & Electronic organizer functions & 87.3 & 75.5 \\
\hline US\$1,500 4,000 & 50.8 & 47.1 & Email \& messaging & 72.0 & 58.8 \\
\hline US $\$ 4,001 \sim 9,000$ & 43.9 & 44.1 & Document \& spreadsheet & & \\
\hline$>$ US $\$ 9,000$ & 1.1 & 0.0 & processing & 53.4 & 49.0 \\
\hline Region & & & Internet Access & 43.9 & 39.2 \\
\hline Asia and South Pacific & 79.9 & 57.8 & Multimedia (audio, video) & 51.9 & 39.2 \\
\hline Americas & 20.1 & 42.2 & Game & 55.0 & 50.0 \\
\hline How much is your PDA? & & & Other & 7.4 & 6.9 \\
\hline
\end{tabular}

\begin{tabular}{lll} 
< US\$299 & 19.5 & 24.5 \\
US\$300 499 & 33.9 & 43.1 \\
US\$500 699 & 28.0 & 17.6 \\
$>$ US\$700 & 18.5 & 14.7 \\
\hline
\end{tabular}

Notes: 1. MS - Users of Microsoft OS-based Products; 2. Palm: Users of Palm OS-based Products; 3. All numbers are in percentages. 
Table 2: Correlation Matrices and Descriptive Statistics of Microsoft and Palm Sample

\begin{tabular}{|c|c|c|c|c|c|c|c|c|c|c|c|c|c|c|}
\hline Variables & US & PT & $\mathbf{A P}$ & PD & $\mathbf{C N}$ & $\mathbf{E U}$ & OP & AG & ED & GD & $\mathbf{P R}$ & IN & UT & $\begin{array}{l}\mathbf{F} \\
\mathbf{R} \\
\end{array}$ \\
\hline Mean & 3.38 & 3.26 & 3.61 & 3.61 & 3.25 & 3.78 & 3.62 & 2.82 & & & & & & \\
\hline Standard Deviation & 0.97 & 0.89 & 0.73 & 0.77 & 0.86 & 1.00 & 0.79 & 0.53 & & & & & & \\
\hline Upgradeability/Supports (US) & 1 & & & & & & & & & & & & & \\
\hline Portability (PT) & $0.17 * *$ & 1 & & & & & & & & & & & & \\
\hline $\begin{array}{l}\text { Application Performance } \\
\text { (AP) }\end{array}$ & $0.55 * * *$ & 0.11 & 1 & & & & & & & & & & & \\
\hline Design (PD) & $0.20 * * *$ & $0.40 * * *$ & $\begin{array}{l}0.15^{*} \\
0.24 * *\end{array}$ & 1 & & & & & & & & & & \\
\hline Connectivity $(\mathrm{CN})$ & $0.29 * * *$ & 0.02 & $*$ & $\begin{array}{l}0.09 \\
0.25^{* *}\end{array}$ & $\begin{array}{l}1 \\
0.22 * *\end{array}$ & & & & & & & & & \\
\hline Ease of Use (EU) & 0.10 & 0.03 & 0.05 & $\begin{array}{l}* \\
0.24 * *\end{array}$ & $*$ & 1 & & & & & & & & \\
\hline Overall Performance (OP) & $0.22 * * *$ & $0.49 * * *$ & 0.11 & $*$ & 0.06 & 0.10 & 1 & & & & & & & \\
\hline Age (AG) & 0.05 & 0.04 & -0.02 & 0.04 & 0.07 & 0.07 & 0.025 & 1 & & & & & & \\
\hline Level of Education (ED) & -0.01 & -0.00 & 0.06 & -0.03 & 0.06 & $\begin{array}{l}0.00 \\
-\end{array}$ & -0.04 & -0.01 & $\begin{array}{l}1 \\
0.26^{* *}\end{array}$ & & & & & \\
\hline $\operatorname{Sex}(G D)$ & -0.01 & 0.02 & -0.01 & -0.06 & 0.03 & $0.12^{*}$ & -0.01 & $-0.13^{*}$ & $*$ & 1 & & & & \\
\hline PDA Price (PR) & 0.07 & -0.00 & 0.01 & 0.02 & 0.05 & 0.07 & 0.05 & $\begin{array}{l}0.00 \\
0.27 * *\end{array}$ & 0.01 & -0.04 & 1 & & & \\
\hline Income (IN) & -0.01 & -0.07 & -0.01 & 0.03 & 0.02 & 0.01 & -0.05 & $*$ & $0.17 * *$ & 0.02 & -0.03 & 1 & & \\
\hline Use time (UT) & -0.05 & -0.03 & -0.07 & -0.06 & 0.04 & -0.03 & 0.00 & 0.04 & 0.01 & 0.01 & -0.06 & 0.10 & 1 & \\
\hline Frequency (FR) & -0.08 & -0.00 & $-0.12 *$ & -0.04 & 0.05 & -0.02 & -0.05 & $0.12 *$ & -0.02 & 0.05 & $\begin{array}{l}- \\
0.51 * * \\
*\end{array}$ & $\begin{array}{l}0.12 \\
* \\
\end{array}$ & 0.06 & 1 \\
\hline
\end{tabular}

Notes: * $\mathrm{P}<0.05 ; * * \mathrm{P}<0.01 ; * * * \mathrm{P}<0.001$ 


\section{Sample Profile}

Table 1 reports sample characteristics by two types of PDA users (Microsoft-based and Palm-based). A majority of respondents were male (over 60\%), were young (below 40 years old), had a college degree or higher, and had a monthly income ranging from US\$ 1,500 to 9,000 . A T-test indicated that two groups did not differ in terms of these demographic variables.

The PDA price that respondents paid typically ranged from US\$ 300 to 700 . More than $41 \%$ of respondents used their PDAs everyday with usage durations ranging from five to 30 minutes each time. The four mostly frequently used applications were the electronic organizer function, email and messaging, games, and the document and spreadsheet process. Appropriately $80 \%$ of Microsoft PDAs users and 57.8\% of Palm PDA users were located in Asia and the South Pacific region. The T-test showed that Microsoft Pocket PC -based PDA users applied the following three functions more frequently than Palm OS-based users - electronic organizer (i.e. phone/address book, calendar, task list, note pad), email and messaging, and multimedia (audio, video). Table 2 lists correlations for the nine constructs.

\section{Measure Validation}

As recommended by Anderson and Gerning's (1988), we employed the two-step approach to evaluate the convergent validity for modeled constructs. In the first phase, we ran exploratory factor analysis (EFA) to assess the underlying factor structure of scale items. The results showed that the first factor did not account for a majority of the variance and no general factor in the unrotated factor structure indicated that common method variance was a problem (Podsakoff and Organ 1986). In the second phase, we performed confirmatory factor analysis (CFA) and found that all factor loadings were shown to be greater than the recommended 0.4 cutoff and were statistically significant (Nunnally and Bernstein 1994). (See Table 3). The Chi-square statistic was significant. However, the ratio of chi-square value relative to degree of freedom (1.91) was less than the cutoff point of two. The goodness-of-fit index, adjusted goodness-of-index, normed fit index, non-normed fit index, and comparative fit index were greater than the recommended 0.9; and the root mean square error of approximation (RMSEA) was less than 0.08 and not statistically different from 0.05 (Hair et al 1995). These indices indicated that the model reasonably fit the data. 
Table 3: Regression Analysis Results between Customer Perceived Quality Dimensions and Overall Performance

\begin{tabular}{lccc}
\hline Independent Variables & Standardized Coefficients & t-value & p-value \\
\hline Control Variables & & & \\
Sex & 0.00 & 0.02 & 0.99 \\
Age & 0.00 & 0.03 & 0.97 \\
Education Level & -0.04 & -0.66 & 0.51 \\
Income & -0.01 & -0.25 & 0.80 \\
Product Price & 0.02 & 0.34 & 0.73 \\
Usage Frequency & -0.03 & -0.46 & 0.65 \\
Usage Intensity & 0.03 & 0.46 & 0.65 \\
Independent variables & & & \\
Upgradeability/Supports & 0.17 & 2.54 & $0.01^{*}$ \\
Portability & 0.36 & 6.10 & $0.00^{* *}$ \\
Application Performance & 0.03 & 0.48 & 0.63 \\
Design & 0.06 & 0.90 & 0.37 \\
Connectivity & 0.00 & 0.03 & 0.98 \\
Ease of Use & 0.06 & 1.06 & 0.29 \\
\hline
\end{tabular}

Note : 1. Dependent Variable: Customer Perceived Overall Product Performance (F $=5.51$, d.f. $=13$, Significant $=0.000, \mathrm{R}^{2}=0.21$, Adjusted $\mathrm{R}^{2}=0.17$ )

2. $* \mathrm{P}<0.05 ; * * \mathrm{P}<0.001$.

We examined the internal validity of our measurement model by calculating the composite reliability (Fornell and Larcker 1981). All the composite reliabilities were above the recommended 0.7 (Nunnally and Bernstein 1994). Discriminant validity of measures was evidenced by two facts. First, we found that the correlation among indicators of each construct was greater than that between a construct and any other construct. Second, each indicator loaded higher on the variable of interest than on any other construct.

\section{Results}

\section{Examining the Relative Importance of Quality Dimensions}

We ran a regression analysis to investigate the relative importance of the six dimensions of quality attributes, along with seven control variables, affecting overall NPD performance. Pursuant to the initial regression run, we examined the standardized residual of each variable and fail to detect any outliers. The average score of all scale item ratings within a given factor was utilized to form measures of six independent variables. We found that parameters were stable when the regression analyses were repeated with $70 \%, 80 \%$, and $90 \%$ of randomly selected cases from the sample. This finding, along with the clean factor loadings of explanatory variables, suggests that multicollinearity is unlikely to affect interpretation of the findings. 
Table 3 demonstrates the results of the regression analysis. The coefficients of determination $\left(\mathrm{R}^{2}\right)$ were $20.6 \%$, while the $\mathrm{F}$ values of both equations were 5.56 (significant at $\alpha=0.000$ level). Therefore, the regression equation achieved a reasonable level of goodness of fit in predicting the variance of overall NPD performance relative to six quality dimensions and seven control variables. As far as the relative importance of the quality dimensions is concerned, the portability factor carried the heaviest weight, followed by upgradeability. The remaining four factors along with seven control variables appear not to be statistically significant in affecting customer perceived overall NP performance. These findings partially supported H1 but failed to support H2.

Table 4: CFA Results of on Perceived Quality Dimensions of PDA Products

\begin{tabular}{|c|c|c|c|c|}
\hline Constructs and Scale Items & Loading & T-Value & $\mathbf{C R}$ & $\alpha$ \\
\hline Application Performance & & & 0.78 & 0.72 \\
\hline 1. The software operating system is very stable & 0.47 & 7.87 & & \\
\hline 2. The applications are very useful to me & 0.82 & 16.45 & & \\
\hline 3. The PDA provides a wide range of applications & 0.87 & 17.28 & & \\
\hline Upgradeability/Support & & & 0.85 & 0.86 \\
\hline $\begin{array}{l}\text { 1. Advanced features like multimedia or internet access } \\
\text { are well supported }\end{array}$ & 0.76 & 16.25 & & \\
\hline 2. New features can be added or downloaded easily & 0.94 & 22.10 & & \\
\hline 3. System software can be easily upgraded & 0.80 & 16.52 & & \\
\hline 4. Third party support on this PDA is excellent & 0.66 & 13.27 & & \\
\hline Connectivity & & & 0.75 & 0.70 \\
\hline 1. It is very easy to connect the PDA wirelessly & 0.56 & 10.31 & & \\
\hline 2. The wireless connection is fast & 0.94 & 15.39 & & \\
\hline 3. The wireless connection is reliable & 0.58 & 10.62 & & \\
\hline Ease of Use & & & 0.84 & 0.80 \\
\hline 1. I can use the PDA without reading the manual & 0.93 & 15.40 & & \\
\hline 2. The PDA is very user friendly & 0.77 & 13.32 & & \\
\hline Product Design & & & 0.76 & 0.70 \\
\hline 1. Design of the PDA looks very attractive to me & 0.44 & 7.81 & & \\
\hline 2. The display is of very high quality & 0.88 & 16.71 & & \\
\hline 3. Buttons \& keys are located in the right place & 0.78 & 14.95 & & \\
\hline Portability & & & 0.79 & 0.80 \\
\hline 1. The size is perfect for me & 0.81 & 5.14 & & \\
\hline 2. The weight is perfect for me & 0.81 & 7.33 & & \\
\hline 3. The battery life is perfect for me & 0.61 & 6.76 & & \\
\hline
\end{tabular}




$$
\begin{aligned}
& \text { Model Fit Indices } \\
& \mathrm{X}^{2}=196.76(\mathrm{P}=0.00) \text {, d.f. }=103, \chi^{2} / \text { d.f. }=1.91 \\
& \mathrm{RMSEA}=0.054, \mathrm{GFI}=0.94 \\
& \mathrm{CFI}=0.97, \mathrm{NFI}=0.95, \mathrm{NNFI}=0.96
\end{aligned}
$$

Note: $\mathrm{CR}=$ Composite Reliability; AVE = Average Variance Extracted

\section{Moderated Regression Approach}

Our hypotheses three and four are intended to compare the relative magnitude or significance of predictors across two groups. To examine the moderating effect of product types and regions on the relationships between key product quality attributes and performance evaluation, we followed an analytic procedure of testing moderator effects proposed by Baron and Kenny (1986). One commonly used method, the subgroup regression approach, divides the study sample into two or more groups and runs a regression analysis for each group (Newsom et al. 2001). However, this method suffers several serious flaws including "the failure to take into account group differences due to sampling error, inability to adequately control for variables confounded with group membership, a loss of power due to reduced sample size and/or artificial dichotomization, less stable regression estimates, and difficulties with standardization." (Newsom et al. 2001, p. 28). Thus, we decided to employ the strongly recommended method, the moderated regression approach which overcomes the above problems (Aiken and West 1991; Newsom wt al. 2001), to test the equivalence of regression coefficients.

\section{The Moderating Effect of Product Types and Regions}

Our $\mathrm{H} 3 \mathrm{a}$ and $\mathrm{H} 3 \mathrm{~b}$ focus on the moderating impacts of two contingency variables product types and regions, on the relationship of key product attributes and customer overall performance evaluation. Each construct with multi-items was measured by a single index by averaging items scores on each construct. Initially, we made a regression of overall performance with both control variables and independent variables (see short model in Table 4). To avoid the multicollinearity issue, we mean-centered the scores of all independent variables and the moderator variables. Further, we used variance inflation factors to confirm there is no multicollinearity among tested variables. Variance inflation factors are a scaled version of the multiple correlation coefficients between one variable and the rest of the independent variables. The results of all variance inflation factors were below the cutoff value of 10 and failed to support multicollinearity among the variables (Aiken and West 1991). Thus, we formed six product terms which were included as interaction variables in the large models.

Results in Tables 4 indicate that both portability $(\beta=0.17$ and 0.17$)$ and upgradeability and supports $(\beta=0.37$ and 0.36$)$ significantly impacted overall performance in the short models. The "upgradeability and supports" dimension had no significant effect when six product terms were added to a large model for two regional groups. Control variables, both demographic variables and usage behavior variables, were found to have no impact 
on performance evaluation. The incremental $\mathrm{R}$ square values for both two large models were not significant $(\Delta \mathrm{F}=1.95, \alpha<0.05$; and $\Delta \mathrm{F}=1.95, \alpha<0.05$ respectively). Furthermore, the coefficient of each interaction variable was not significant. We also ran the Chow test (1960) and found that there was no structural change between two groups by examining the statistical significance of the difference in the size of regression coefficients. Thus, we conclude that neither users nor regions had any moderating effect on the relationships between key product attributes and overall performance. 0.06). In other words, $\mathrm{H} 3 \mathrm{a}$ and $\mathrm{H} 3 \mathrm{~b}$ are supported.

Table 4: CFA Results of on Perceived Quality Dimensions of PDA Products

\begin{tabular}{|c|c|c|c|c|}
\hline Constructs and Scale Items & Loading & T-Value & $\mathbf{C R}$ & $\alpha$ \\
\hline Application Performance & & & 0.78 & 0.72 \\
\hline 1. The software operating system is very stable & 0.47 & 7.87 & & \\
\hline 2. The applications are very useful to me & 0.82 & 16.45 & & \\
\hline 3. The PDA provides a wide range of applications & 0.87 & 17.28 & & \\
\hline Upgradeability/Support & & & 0.85 & 0.86 \\
\hline $\begin{array}{l}\text { 1. Advanced features like multimedia or internet access } \\
\text { are well supported }\end{array}$ & 0.76 & 16.25 & & \\
\hline 2. New features can be added or downloaded easily & 0.94 & 22.10 & & \\
\hline 3. System software can be easily upgraded & 0.80 & 16.52 & & \\
\hline 4. Third party support on this PDA is excellent & 0.66 & 13.27 & & \\
\hline Connectivity & & & 0.75 & 0.70 \\
\hline 1. It is very easy to connect the PDA wirelessly & 0.56 & 10.31 & & \\
\hline 2. The wireless connection is fast & 0.94 & 15.39 & & \\
\hline 3. The wireless connection is reliable & 0.58 & 10.62 & & \\
\hline Ease of Use & & & 0.84 & 0.80 \\
\hline 1. I can use the PDA without reading the manual & 0.93 & 15.40 & & \\
\hline 2. The PDA is very user friendly & 0.77 & 13.32 & & \\
\hline Product Design & & & 0.76 & 0.70 \\
\hline 1. Design of the PDA looks very attractive to me & 0.44 & 7.81 & & \\
\hline 2. The display is of very high quality & 0.88 & 16.71 & & \\
\hline 3. Buttons \& keys are located in the right place & 0.78 & 14.95 & & \\
\hline Portability & & & 0.79 & 0.80 \\
\hline 1. The size is perfect for me & 0.81 & 5.14 & & \\
\hline 2. The weight is perfect for me & 0.81 & 7.33 & & \\
\hline 3. The battery life is perfect for me & 0.61 & 6.76 & & \\
\hline
\end{tabular}




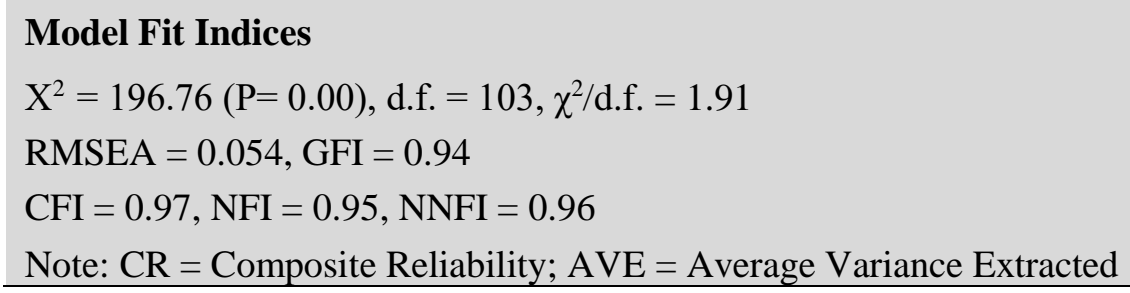

\section{The Moderating Effect of Applications}

Our H4 posits that product applications will have moderating effects on overall performance evaluations through major product attributes. Respondents were asked to choose major applications for their PDAs. When the application was chosen, we coded it as " 1 "; otherwise it was coded as " 0 ". Using the same procedure described above, we ran a moderated regression analysis for each application. Due to the limitation of space, we only listed six larger models which included six product terms. Our short models indicate that two dimensions, upgradeability/support and portability, are the most important and significant predictors of overall performance across all application types. Regarding moderating effects of application types, results in Table 5 show that the increased $\mathrm{R}^{2} \mathrm{~s}$ are insignificant across six applications. Again, portability significantly effects overall performance across all applications. Thus, various applications virtually exercise no moderating effects on the relationships between key dimensions and overall performance. 
Table 5: Moderated Regression Analysis of the Effect of Product Types and Regions on Performance

\begin{tabular}{|c|c|c|c|c|c|c|c|c|}
\hline & \multicolumn{4}{|c|}{$\begin{array}{l}\text { Product Types } \\
\text { (Microsoft vs Palm OS) }\end{array}$} & \multicolumn{4}{|c|}{$\begin{array}{l}\text { Regions } \\
\text { (Asia \&South Pacific vs Americas) }\end{array}$} \\
\hline & \multicolumn{2}{|c|}{ Short Model } & \multicolumn{2}{|c|}{ Large Model } & \multicolumn{2}{|c|}{ Short Model } & \multicolumn{2}{|c|}{ Large Model } \\
\hline & $\beta^{*}$ & t-value & $\beta^{*}$ & t-value & $\beta^{*}$ & t-value & $\beta^{*}$ & t-value \\
\hline \multicolumn{9}{|l|}{ Control Variables } \\
\hline Sex & 0.00 & 0.05 & 0.01 & 0.19 & 0.00 & 0.01 & 0.00 & 0.07 \\
\hline Age & 0.00 & 0.02 & 0.00 & -0.06 & 0.00 & 0.04 & 0.00 & -0.07 \\
\hline Education Level & -0.04 & -0.64 & -0.03 & -0.46 & -0.04 & -0.64 & -0.04 & -0.71 \\
\hline Income & -0.02 & -0.26 & -0.02 & -0.31 & -0.02 & -0.26 & -0.01 & -0.16 \\
\hline Product Price & 0.02 & 0.30 & 0.00 & 0.01 & 0.02 & 0.35 & 0.02 & 0.34 \\
\hline Usage Frequency & -0.03 & -0.46 & -0.04 & -0.63 & -0.03 & -0.46 & -0.03 & -0.38 \\
\hline Usage Intensity & 0.02 & 0.37 & 0.02 & 0.32 & 0.03 & 0.46 & 0.03 & 0.58 \\
\hline \multicolumn{9}{|l|}{ Independent variables } \\
\hline Upgradeability/Supports & 0.17 & $2.53^{\mathrm{a}}$ & 0.21 & $2.67^{\mathrm{b}}$ & 0.17 & $2.53^{\mathrm{a}}$ & 0.14 & 1.87 \\
\hline Portability & 0.37 & $6.11^{\mathrm{c}}$ & 0.37 & $4.80^{\mathrm{c}}$ & 0.36 & $6.08^{c}$ & 0.42 & $5.77^{\mathrm{c}}$ \\
\hline Application Performance & -0.03 & -0.52 & -0.08 & -1.05 & -0.03 & -0.48 & -0.01 & -0.18 \\
\hline Design & 0.05 & 0.86 & 0.08 & 0.93 & 0.06 & 0.90 & 0.08 & 1.06 \\
\hline Connectivity & -0.01 & -0.08 & 0.05 & 0.68 & 0.00 & -0.03 & -0.01 & -0.16 \\
\hline Ease of Use & 0.06 & 1.08 & -0.02 & -0.27 & 0.06 & 1.06 & 0.07 & 0.99 \\
\hline Product Types & -0.03 & -0.46 & -0.04 & -0.70 & 0.01 & 0.10 & -0.05 & -0.20 \\
\hline \multicolumn{9}{|l|}{ Interactions } \\
\hline \multicolumn{9}{|l|}{ Product Types } \\
\hline x Upgradeability/Supports & & & -0.10 & -1.28 & & & 0.05 & 0.63 \\
\hline x Portability & & & -0.01 & -0.16 & & & -0.10 & -1.46 \\
\hline x Application Performance & & & 0.10 & 1.18 & & & -0.02 & -0.21 \\
\hline x Design & & & -0.04 & -0.53 & & & -0.06 & -0.77 \\
\hline x Connectivity & & & -0.09 & -1.40 & & & 0.05 & 0.22 \\
\hline $\mathrm{x}$ Ease of Use & & & 0.14 & 1.85 & & & 0.00 & 0.01 \\
\hline $\mathrm{R}$ & 0.454 & & 0.475 & & 0.454 & & 0.468 & \\
\hline $\mathrm{R}^{2}$ & 0.207 & & 0.226 & & 0.206 & & 0.219 & \\
\hline Adjusted $\mathrm{R}^{2}$ & 0.166 & & 0.168 & & 0.166 & & 0.161 & \\
\hline F-value & $5.11^{\mathrm{c}}$ & & $3.92^{\mathrm{c}}$ & & $5.10^{c}$ & & $3.76^{c}$ & \\
\hline Incremental $\mathrm{R}^{2}$ & & & 0.019 & & & & 0.013 & \\
\hline F-value for Incremental $\mathrm{R}^{2}$ & & & 1.109 & & & & 0.752 & \\
\hline $\mathrm{N}$ & 291 & & 291 & & 291 & & 291 & \\
\hline
\end{tabular}

Notes: *: Standardized value. a: $\mathrm{P}<0.05$; b: $\mathrm{P}<0.01$; c: $\mathrm{P}<0.001$ 
Table 5: Moderated Regression Analysis of the Effect of Product Applications on Overall Performance

\begin{tabular}{|c|c|c|c|c|c|c|c|c|c|c|c|}
\hline & $\mathrm{EO}$ & & EM & & DSP & & IA & & MM & & GM \\
\hline Variables & $\beta^{*}$ & & $\beta^{*}$ & & $\beta^{*}$ & & $\beta^{*}$ & & $\beta^{*}$ & & $\beta^{*}$ \\
\hline \multicolumn{12}{|l|}{ Control Variables } \\
\hline Sex & 0.00 & & 0.00 & & 0.00 & & 0.01 & & 0.00 & & 0.01 \\
\hline Age & 0.00 & & 0.00 & & 0.01 & & 0.00 & & -0.01 & & 0.00 \\
\hline Education Level & -0.03 & & -0.04 & & -0.03 & & -0.05 & & -0.03 & & -0.04 \\
\hline Income & -0.01 & & 0.00 & & -0.02 & & -0.02 & & 0.00 & & -0.02 \\
\hline Product Price & 0.03 & & 0.03 & & 0.02 & & 0.04 & & -0.01 & & 0.02 \\
\hline Usage Frequency & -0.01 & & -0.02 & & -0.02 & & -0.03 & & -0.02 & & -0.01 \\
\hline Usage Intensity & 0.02 & & 0.03 & & 0.02 & & 0.03 & & 0.03 & & 0.02 \\
\hline \multicolumn{12}{|l|}{ Independent variables } \\
\hline Upgradeability/Supports & 0.21 & & 0.04 & & 0.16 & & 0.05 & & 0.14 & & 0.19 \\
\hline Portability & $0.48^{b}$ & & $0.37^{\mathrm{b}}$ & & $0.39^{\mathrm{c}}$ & & $0.37^{\mathrm{c}}$ & & $0.39^{\mathrm{c}}$ & & $0.46^{\mathrm{c}}$ \\
\hline Application Performance & 0.08 & & 0.02 & & 0.04 & & 0.05 & & -0.02 & & 0.01 \\
\hline Design & $-0.32^{\mathrm{a}}$ & & -0.06 & & 0.04 & & 0.08 & & -0.06 & & -0.02 \\
\hline Connectivity & 0.01 & & 0.03 & & -0.02 & & -0.01 & & -0.01 & & -0.03 \\
\hline Ease of Use & 0.05 & & 0.16 & & 0.09 & & 0.14 & & 0.08 & & $0.20^{\mathrm{a}}$ \\
\hline EO & 0.03 & EM & 0.04 & DSP & 0.02 & IA & 0.05 & MM & $0.14^{\mathrm{a}}$ & GM & -0.01 \\
\hline \multicolumn{12}{|l|}{ Interactions } \\
\hline x Upgradeability/Supports & -0.05 & & 0.17 & & 0.01 & & 0.18 & & 0.01 & & -0.04 \\
\hline x Portability & -0.13 & & -0.02 & & -0.05 & & 0.02 & & -0.02 & & -0.13 \\
\hline x Application Performance & -0.11 & & -0.08 & & -0.10 & & -0.13 & & 0.00 & & -0.03 \\
\hline $\mathrm{x}$ Design & $0.41^{\mathrm{a}}$ & & 0.13 & & 0.03 & & -0.06 & & 0.14 & & 0.11 \\
\hline $\mathrm{x}$ Connectivity & -0.02 & & -0.04 & & 0.01 & & -0.02 & & 0.00 & & 0.03 \\
\hline $\mathrm{x}$ Ease of Use & 0.02 & & -0.12 & & -0.05 & & -0.10 & & -0.02 & & -0.19 \\
\hline $\mathrm{R}^{2}$ & 0.232 & & 0.220 & & 0.212 & & 0.226 & & 0.231 & & 0.227 \\
\hline Adjusted $\mathrm{R}^{2}$ & 0.175 & & 0.162 & & 0.154 & & 0.169 & & 0.174 & & 0.170 \\
\hline F-value & $4.06^{\mathrm{c}}$ & & $3.79^{c}$ & & $3.62^{\mathrm{c}}$ & & $3.94^{\mathrm{c}}$ & & $4.04^{\mathrm{c}}$ & & $3.96^{\mathrm{c}}$ \\
\hline Incremental $\mathrm{R}^{2}$ & 0.026 & & 0.012 & & 0.006 & & 0.018 & & 0.007 & & 0.021 \\
\hline F-value for Incremental $R^{2}$ & 1.529 & & 0.695 & & 0.344 & & 1.050 & & 0.411 & & 1.227 \\
\hline $\mathrm{N}$ & 161 & & 133 & & 98 & & 80 & & 95 & & 100 \\
\hline
\end{tabular}

Notes: $1 . *$ : Standardized value.

2. a: $\mathrm{P}<0.05$; b: $\mathrm{P}<0.01$; $\mathrm{c}: \mathrm{P}<0.001$

3. $\mathrm{EO}=$ Electronic Organizer; EM = Email and Messaging; DSP = Document and Spreadsheet

Processing; IA = Internet Access; MM = Multimedia (e.g., audio, video); and GM = Game 
However, adding the contingent variables - product applications - into the main effect does reduce the significant level of "upgradeability/supports" to insignificant. Moreover, they do significantly modify coefficients of some variables. For instance, for the application of "electronic organizer", the "design" factor becomes significant. When the main function of a PDA is "electronic organizer", customers have a desire for attractive design, high quality display, and button and keys in right places. In the same vein, when customers frequently use PDAs to play games, they desire ease of use. It is critical for them to use PDAs without reading the manual so they can enjoy the game feature. Those who like to use the PDA's multimedia functions (e.g., audio and video) significantly increase their rating for overall performance.

\section{Discussion}

This study examines several issues related to attribute-based measures of NPD performance from the customer perspective. After identifying customer perceived key attributes of PDA products, we examined the effect of each attribute, along with sociodemographic and product usage variables relative to overall performance. We further investigated whether the effects of quality attributes on overall evaluation vary in terms of three contingent variables - product types, regions, and product applications

The NPD process involves inputting feedback from customers, before or after commercialization. Our study indicates that identifying customer perceived key attributes of new products is essential to business or product strategies such as improving and repositioning new products. Customer perceived key quality attributes may differ considerably from what the company has emphasized. For instance, this study identified six key attributes perceived by PDA product users - upgradeability and support, portability, application performance, design, connectivity, and ease of use. Customer perceived key product attributes often set a direction for technical advancement. Firms that closely link their technical innovations to customer needs and wants are likely to gain more competitive advantage.

While product quality dimensions do have an effect on overall product performance perceived by customers, not all attributes significantly contribute to customer overall evaluation. In the case of PDAs, among six identified key product attributes, only "portability" and "upgradeability and supports" are the most important and significant factors in determining customer evaluation of overall performance. Since firms usually have limited financial and human resources to keep each attribute perfect, they should place more emphasis on these two aspects. Specifically, customers expect companies to provide strong support for such advanced and complicated features as the multimedia capability. If they desire, customers can add or download new features, and easily upgrade system software. In addition, they demand excellent third party support. As one of the major advantages over personal computers, portability of a PDA product plays a vital role. Companies should pay very close attention to product size, weight, and the duration of battery life. Often, adding unnecessary accessories and complicated applications will enlarge its size, weight and increase frequency of recharge or change of batteries. Thus, the key is to balance the product functions and simplicity of a PDA to 
keep an appropriate level of portability while providing flexibility for customers to select features they prefer.

Furthermore, we have found that the importance of each key product dimension in determining overall product performance does not have any significant difference across companies and geographic locations. The findings indicate that customers actually share some common expectations for a PDA product, no matter which operating systems their products run or how much a firm differentiates its products from others. Thus, a company should pay more attention to attributes perceived by customers in the whole product industry, not just to its own customers. Another implication is that high tech products like PDA products are truly globally oriented. Geographic locations are essentially irrelevant in determining their evaluation.

Although product applications do not have significant moderating effects on the relationship between key quality attributes and overall performance, they do affect the importance of certain product attributes. For instance, the "design' factor becomes significant when customers' main purpose of using a PDA is as a personal organizer. Similarly, the "ease of use" is significant for those who like playing games. We also notice that the more a PDA customer uses the multimedia functions, such as audios and videos, the higher they rate the product performance. In reality, customers seldom use the multimedia function due to its relative complexity. This indicates that company may encourage and help users to explore the multimedia function. Above all, product developers should learn which functions customers tend to use most. In this way, efforts can be devoted to the key attributes that are commonly present in specific applications.

\section{Limitations and Directions for Future Studies}

There are several caveats in this study. Methodologically, our sample sizes, drawn from a list of PDA customers, appeared to be non-proportional to actual PDA product users in terms of geographical locations and product types. This may limit generalization of the findings. Additionally, because of the unique nature of the PDA industry, the study defined PDA product types based on two software brands or operating systems (Microsoft Pocket PC versus Palm OS) on which PDAs run. Future studies, however, may make comparisons in terms of hardware brands or manufacturers including all top five brands - Palm, Handspring, Compaq, RIM, and HP.

While the attribute-based measures do reflect users' perceptions, the essential task for product developers is to clearly understand the existing gaps between a company's original NPD goals and customers' actual perceptions. To provide more useful insights, future studies can examine the gaps among product developers, marketers, and customers, and, consequently, discover the reasons leading to these discrepancies.

As our results have shown, customer perceived key product attribute-based measures do contribute a fair portion of overall performance in the current study. Nevertheless, there are still other important predictors driving superior NPD performance. For instance, 
customer perceived technical innovation, time to market, and product costs may also play a vital role.

Finally, we conducted data analyses at the product level because (1) our study focuses on general issues related to customer-oriented and product attribute-based measures, and (2) the unique nature of the PDA industry (e.g., relatively few competitors, high-tech). Further studies may examine the above issues at the project-level or program-level, similar to traditional performance measures (Griffin and Page 1996).

\section{Acknowledgement}

The author gratefully acknowledges a grant from National Natural Science Foundation of China (project 71672164) and City University of Hong Kong (project 9680194) for financial support.

\section{References}

Aiken, Leona SS. and Stephen G. West (1991), Multiple Regression: Testing and Interpreting Interactions. Newbury Park, CA: Sage Publications.

Anderson, James C. and David W. Gerbing (1988), "Structural Equation Modeling in Practice: A Review and Recommended Two-Step Approach," Psychological Bulletin, 103, 411-23.

Baron, R. M. and Kenny, D.A. (1986), "The Moderator-Mediator Variable Distinction in Social Psychological Research: Conceptual, Strategic, and Statistical Considerations." Journal of Personality and Social Psychology, 46, 1173-1182.

Bharadwaj, Anandhi, Bharadwaj, Sundar and Bendoly, Elliott (forthcoming), "Complementary Drivers of NPD Performance: Cross-Functional Coordination, Information System Capability, and Intelligence Quality," Production and Operations Management.

Bardhan, Indranil R., (2007), "Toward a theory to study the use of collaborative product commerce for product development, Information Technology Management, 8, 167-184.

Brown, S. L. and K. M. Eisenhardt (1995), "Product Development: Past Research, Present Findings, and Future Directions," Academy of Management Review, 20, 343-78.

Chow, Gregory (1960), "Tests of Equality Between Sets of Coefficients in Two Linear Regressions," Econometrica, 28 (3), 591-605.

Cooper, R. G. and E. J. Kleinschmidt (1995), "Benchmarking firms' new product performance and practices," Engineering Management Review (Fall), 112-20.

Cooper, R. G. and S. J. Edgett (1996), "Critical success factors for new financial services," Marketing Management (Fall), 26-37.

Davis, F. D. (1989), "Perceived Usefulness, Perceived Ease of Use, and User Acceptance of Information Technology," MIS Quarterly, 13 (3), 319-40.

Davis, F. D., R. P. Bagozzi, and P. R. Warshaw (1989), "User Acceptance of Computer Technology: A Comparison of Two Theoretical Models," Management Science, 35 (8), 982-1003.

Driva, H, K S Pawar, and U Menon (2000), "Measuring product development performance in manufacturing organizations," International Journal of Production Economics, 63 (2), $147-59$.

Fornell, C. and Larcker, D. (1981), "Evaluating structural equation models with unobservable variables and measurement error," Journal of Marketing Research, 18, 39-50. 
Griffin, A. (1997), "PDMA Research on New Product Development Practices: Updating Trends, and Benchmarking Best Practices," Journal of Product Innovation Management, 14, 42958 .

Griffin, Abbie. and Albert L. Page (1993), "An Interim Report on Measuring Product Development Success and Failure," Journal of Product Innovation Management, 10, 291308.

Griffin, A. and A. L. Page (1996), "PDMA Success Measurement Project: Recommended Measures for Product Development Success and Failure," Journal of Product Innovation Management, 13, 478-96.

Hair, Joseph F., Rolph E. Anderson, Ronald L. Tatham, and William C. Black (1995), Multivariate Data Analysis. NJ: Englewood Cliffs: Prentice Hall.

Hertenstein, Julie H and Marjorie B Platt (1997), "Developing a strategic design culture," Design Management Journal, 8 (2), 10-19.

Hertenstein, Julie H and Marjorie B Platt (2000), "Performance measures and management control in new product development," Accounting Horizons, 14 (3), 303-23.

Hertenstein, Julie H and Marjorie B Platt (1998), "Why product development teams need management accountants," Management Accounting (April), 50-55.

Huang, Xuelai, Geoffrey N. Soutar, and Alan Brown (2004), "Measuring New Product Success: An Empirical Investigation of Australian SMEs," Industrial Marketing Management, 33 (2), 117-123.

Kahn, B. E. and Meyer, R. J. (1991), "Consumer multiattribute judgments under attribute-weight uncertainty," Journal of Consumer Research., 17 (March), 508-22.

Kaplan, R.S. and D.P. Norton (1992), "The balanced scorecard - measures that drive Performance," Harvard Business Review (Jan. -Feb.), 71-79.

Lambert, Denis and Stanley F Slater (1999), "Perspective: First, fast, and on time: The path to success, or is it?," Journal of Product Innovation Management, 16 (5), 427-38.

Langfield-Smith, K (1997), "Management Control Systems and Strategy: A Critical Review," Accounting, Organizations and Society, 22 (2), 207-52.

Ledwith, A., and O'Dwyer, M. (2009), "Market orientation, NPD performance, and organizational performance in small firms", Journal of Product Innovation Management, 26 (6), 652-61.

Newsom, Jason T., Holly G. Prigerson, Richard Schulz, and Charles F. Reynolds III (2001), "Group Differences in Prediction in Aging Research: Statistical, Methodological, and Conceptual Issues." Working Paper, Portland, OR: Portland State University, 1-45.

Nunnally, J.C. and I. H. Bernstein (1994), Psychometric Theory. New York: McGraw-Hall.

Podsakoff, Philip M. and Dennis W. Organ (1986), "Self-Reports in Organizational Research: Problems and Prospects." Journal of Management, 12 (Winter), 531-43.

Sanbonmatsu, D. M., F. R. Kardes, and B. D. Gibson (1991), "The role of attribute knowledge and overall evaluations in comparative judgment," Organizational Behavior and Human Decision Processes, 48 (131-146).

Sandmeier, Patricia, Morrison, Pamela D. and Gassmann, Oliver (2010), "Integrating Customers in Product Innovation: Lessons from Industrial Development Contractors and In-House Contractors in Rapidly Changing Customer Markets," Creativity and Innovation Management, 19 (2), 89-106.

Wedel, M. and W. A. Kamakura (1998), Market Segmentation: Conceptual and Methodological Foundations. Dodrecht, the Netherlands.: Kluwer Academic Publishers.

Wright, P. (1975), "Consumer choice strategies: simplifying vs. optimizing," Journal of Marketing Research, 12 (Feb.), 60-67.

Zhang, Shi and Gavan J. Fitzsimons (1999), "Choice-Process Satisfaction: The Influence of Attribute Alignability and Option Limitation," Organizational Behavior and Human Decision Processes, 77 (3), 192-214. 
Yang, 2018 